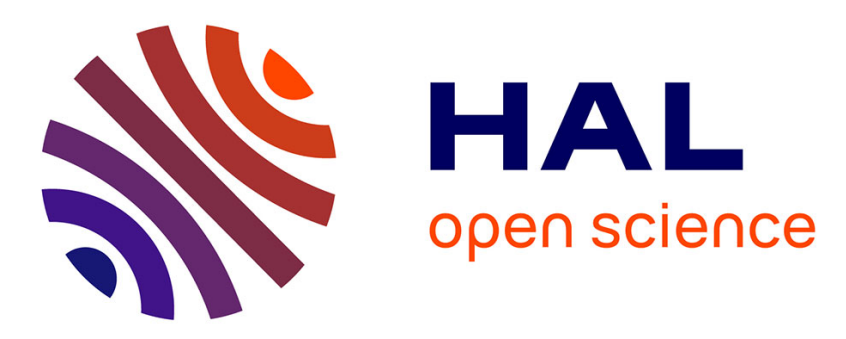

\title{
Kinetic Modelling of High Density PolyEthylene Pyrolysis: Part 1. Comparison of existing models
}

Nicolas Gascoin, Ana Navarro-Rodriguez, Philippe Gillard, Alexandre

Mangeot

\section{- To cite this version:}

Nicolas Gascoin, Ana Navarro-Rodriguez, Philippe Gillard, Alexandre Mangeot. Kinetic Modelling of High Density PolyEthylene Pyrolysis: Part 1. Comparison of existing models. Polymer Degradation and Stability, 2012, pp.2012, 1-9. 10.1016/j.polymdegradstab.2012.05.008 . hal-00705543

\section{HAL Id: hal-00705543 \\ https://hal.science/hal-00705543}

Submitted on 11 Jun 2012

HAL is a multi-disciplinary open access archive for the deposit and dissemination of scientific research documents, whether they are published or not. The documents may come from teaching and research institutions in France or abroad, or from public or private research centers.
L'archive ouverte pluridisciplinaire HAL, est destinée au dépôt et à la diffusion de documents scientifiques de niveau recherche, publiés ou non, émanant des établissements d'enseignement et de recherche français ou étrangers, des laboratoires publics ou privés. 


\section{Accepted Manuscript}

Kinetic Modelling of High Density PolyEthylene Pyrolysis: Part 1. Comparison of existing models

N. Gascoin, A. Navarro-Rodriguez, P. Gillard, A. Mangeot

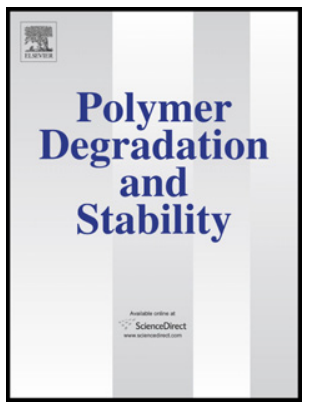

PII:

S0141-3910(12)00173-5

DOI:

10.1016/j.polymdegradstab.2012.05.008

Reference: $\quad$ PDST 6657

To appear in: Polymer Degradation and Stability

Received Date: 31 January 2012

Revised Date: 16 April 2012

Accepted Date: 15 May 2012

Please cite this article as: Gascoin N, Navarro-Rodriguez A, Gillard P, Mangeot A, Kinetic Modelling of High Density PolyEthylene Pyrolysis: Part 1. Comparison of existing models, Polymer Degradation and Stability (2012), doi: 10.1016/j.polymdegradstab.2012.05.008.

This is a PDF file of an unedited manuscript that has been accepted for publication. As a service to our customers we are providing this early version of the manuscript. The manuscript will undergo copyediting, typesetting, and review of the resulting proof before it is published in its final form. Please note that during the production process errors may be discovered which could affect the content, and all legal disclaimers that apply to the journal pertain. 


\section{Part 1. Comparison of existing models.}

\author{
N. Gascoin ${ }^{1}$, A. Navarro-Rodriguez ${ }^{2}$, P.Gillard ${ }^{3}$, A. Mangeot ${ }^{4}$ \\ University of Orléans, 63 avenue de Lattre de Tassigny, 18020 Bourges, France
}

High Density Poly-Ethylene (HDPE) is one of the possible solid fuels to be used in hybrid rocket propulsion, despite its low ability of rapidly producing combustible gas. This drawback may be balanced by the auto-ignition delay of the pyrolysis products, which would conduct to the increase of the heat release rate in the engine and thus to the one of the regression rate. Six single and multi steps HDPE pyrolysis mechanisms from the literature are compared in this paper to determine their ability to predict the production of byproducts and the consumption of HDPE. Transient pyrolysis is observed from $650 \mathrm{~K}$ to $823 \mathrm{~K}$ at atmospheric pressure and discrepancies up to a factor 7 are found between these mechanisms, despite they are all derived from experimental data. One mechanism is finally selected to conduct a parametric study in more realistic operating conditions for hybrid rocket, up to $1700 \mathrm{~K}$ and 100 bar. Identifying and quantifying pyrolysis products are necessary to study their combustion with another detailed mechanism.

Keywords: Polyethylene; pyrolysis; kinetic mechanism; hybrid propulsion.

${ }^{1}$ Corresponding author : Nicolas.Gascoin@bourges.univ-orleans.fr, Associate Professor, Tel.: +33 248238 473; Fax: +33248 238 471, 63 avenue de Lattre de Tassigny, 18020 Bourges Cedex FRANCE

${ }^{2}$ Research Engineer

${ }^{3}$ Full Professor

${ }^{4} \mathrm{Ph} . \mathrm{D}$. Student 


\section{Introduction}

Nowadays, the interest in polymeric material pyrolysis is increasing. Two principal application fields are found: innovative polymer recycling techniques [1],[2],[3] and solid fuel for aerospace applications [4]. In the first one, detailed chemistry allows controlling the final recycling products through the regulation of the pyrolysis temperature. In the second one, it allows estimating the time constant of involved driving phenomena (multicomponent diffusion, auto-ignition delay) as a function of operating conditions. The study developed in this paper specifically focuses on the last field but it is intimately linked to the first one since no kinetic chemistry work is available on HDPE -to the authors' knowledge- for propulsion need. It is thus required to take advantage of studies developed in other fields of research despite the operating conditions are not the same.

\subsection{Need of chemistry in hybrid propulsion}

During polymer's recycling, the applied temperature and the way to heat-up polymeric material both determine which final products are obtained. The degradation of plastics in a variety of different reactor types has been investigated at various processing scales [5]. Polyethylene and polypropylene are the major components of plastic wastes from domestic refuse. Until now, plastic wastes have been mainly disposed of by landfill or incineration, which are inefficient and highly contaminating techniques [6]. These processes are not acceptable under policies which focus on efficient recovery of raw material and energy. Pyrolysis and gasification processes are promising routes for optimal material recycling. Moreover, pyrolysis of plastics at different temperatures allows the treatment of polymers with simultaneous decomposition and separation. Combustible, gases and energy can be obtained at the same time with only one recycling process. Logically, the first step for a suitable design of any pyrolysis reactor intended to plastic recycling is a high knowledge and a control of the involved kinetics.

Hybrid engines are generally composed of an oxidizer tank connected by a valve to the solid fuel tank, which ensures the function of the combustion chamber [4]. One to several channels are drilled in the solid fuel to achieve the combustion with injected gaseous oxidiser [4]. The combustible gas is produced by the pyrolysis of the solid fuel thanks to the heat release due to the combustion. The decomposition products react with the oxidizer depending on their nature, increasing the flame temperature, and favouring pyrolysis process. This brief description could be extended due to the complexity of hybrid engine (injection mode and technologies, multi-ports grain, thermal and 
mechanical effects in the solid fuel [4]). Numerous fuels have been investigated since the 1970's and polyethylene is one of them because of safety, cost and environment-friendliness reasons, despite its so-called regression rate (related to the conversion rate) remains low, particularly when estimated with low heating rate systems [7]. It can be noted that High Density PolyEthylene is preferred to standard polyethylene for specific weight reason.

The most important particularity of the hybrid combustion behaviour is the axial dependency of the combustion. The equivalence ratio varies along the length of the fuel grain, so the temperature and the regression rate fluctuate. There is also a time dependency because the cross-section of the gas flow increases due to the solid regression. The dynamics of the chemical, thermal and hydraulic phenomena changes during the functioning. To understand the physics of the process and the fuel-oxidiser interaction, a transient and reactive numerical simulation is required. Such a Computational Fluid Dynamics code (CFD) should consider the chemistry with a particular interest since it is the driving process of the system (heat release and combustible generation) [7]. For this reason, this work is intended to determine if existing detailed kinetic models from open literature can be used for this purpose. Their validity for hybrid application must be verified and their compatibility with later combustion study is mandatory.

\subsection{Available kinetic mechanisms for HDPE pyrolysis}

As it was pointed out by Mastral et al. [8], only few kinetic data are available in open literature on HDPE pyrolysis. Moreover, Poutsma [9] clearly showed the inconsistency of numerous experimental results from the literature. Concerning the pyrolysis modelling, several authors worked for a recycling purpose [1],[2],[5],[6]. Because of different aims, the range of validity (in terms of operating conditions) differs from one mechanism to an other one. The set of considered species vary and their consumption is rarely taken into account. Since they can be complementary, they all are useful to better understand the phenomena. Nevertheless, it is not possible for consistency reason to use them all in a CFD code and, as a consequence, it is necessary to determine the most relevant under hybrid rocket engine conditions. The available mechanisms are either analytical single step Arrhenius laws or detailed kinetic mechanisms with primary and secondary reaction sets. The polymer pyrolysis usually involves three general reaction pathways, depending on the polymer nature [10]:

- Unzipping (UZ): successive enchained $\beta$-scission reactions, which yield monomer from the polymer chain.

- Backbiting (BB): specific intramolecular hydrogen transfer reactions followed by mid-chain $\beta$-scission to yield a series of specific low molecular weight products (LMWPs). 
- Random scission (RS): involves intermolecular hydrogen transfer followed by mid-chain $\beta$-scission to yield a diverse set of LMWP.

Depending on the predominant chemical bond in polymeric material, there will be a dominancy of one of the three degradation modes. Polyethylene is especially susceptible to both BB and RS pathways because every midchain hydrogen yields an equally stable secondary carbon radical. Understanding the competition between RS and BB is important for fully understanding the polyethylene pyrolysis mechanism [1]. In addition, the particular role of free radicals in the pyrolysis process should be addressed since the elaboration of kinetic scheme clearly depends on these compounds [11].

The kinetic mechanism of Németh et al. [12] considers most of these possible reaction pathways. The polymer thermal degradation is accounted by 7541 reactions and 1014 species. To develop their mechanism, the authors took most of the possible reactions into account before removing the less important ones. This mechanism can be integrated with a stiff differential solver in order to have a numerical simulation of the physical process. A strong domination of alkenes production is verified [12]. The authors compared numerical data to experimental product distribution obtained in a micropyrolizer reactor at $500{ }^{\circ} \mathrm{C}$ and $20 \mathrm{~s}$ of reaction time. The model fairly predicts the degradation of polymer at low conversion rate despite $13 \%$ of uncertainty is found for propane and up to a factor 6 for butane for example. Further researches are needed to improve the accuracy of this mechanism at higher conversion rate. A second detailed mechanism has been found [1]. Levine and Broadbelt elaborated a kinetic scheme with 11000 reactions and 151 species on the basis of previous experiments [13]. They used a population balance based lumping technique to limit the number of polymeric species, which is of strong interest for CFD application. Indeed, the number of species plays a role in the computing cost. Limiting it is favourable for future numerical simulations. The way the lumping of heavy species could be achieved will be discussed in a companion paper, where the major role of alkenes will be detailed [14]. An excellent agreement between numerical results and experimental data was obtained by Levine and Broadbelt and the mechanism is considered to be validated for the temperature range $693 \mathrm{~K}-773 \mathrm{~K}$. They demonstrated dominancy of RS reactions for thermal degradation of HDPE. Unfortunately, the present authors faced a major difficulty to test the mechanism of Levine and Broadbelt since it is not freely available, even on demand (no ASCII file compatible with CHEMKIN like programs). Thus, it has not been possible to test it in the present work. In addition, the final aim of the present study is to implement a kinetic mechanism in a CFD code. As a result, considering available mechanism is the first requirement. 
Reduced mechanisms are also available. Al-Salem and Lettieri [2] proposed a simple model, where kinetic

101

102

103

104

105

106

107

108

109

110

111

112

113

114

115

116

117

118

119

120

121

122

123

124

125 parameters are obtained from experimental data under isothermal conditions. With only 7 basics reactions and 5 groups of species, this mechanism can be easily integrated in a CFD code. Nevertheless, it is not suitable for hybrid rocket application. The main reason is that they considered a gas entity without taking its chemical composition into account. To perform combustion studies, the gas composition is of first importance because the auto-ignition delay will vary depending on the species (a large difference exists between acetylene and methane for example). Elordi $e t$ al. [15] proposed a similar size mechanism, which has been validated for a larger temperature range (723 $\mathrm{K}$ to $988 \mathrm{~K})$ than the one of Salem et al. ( $773 \mathrm{~K}-873 \mathrm{~K})$. It is based on the Westerhout's kinetic mechanism [3] but it fits experimental data with better accuracy. Nevertheless, with 6 basics reactions and 6 groups of species, Elordi's mechanism is again too much simplified. It does not allow considering the variation of gas products composition as a function of the operating conditions. The same drawback is observed for the work of Johannes et al. [16]. They developed a simple kinetic model with 4 groups of species and 8 basics reactions, which takes into account the nonlinear effect of temperature increase during material pyrolysis. Similarly, Mastral et al. [8] studied HDPE pyrolysis up to $973 \mathrm{~K}$ in fluidised bed reactor for residence time lower than $2.6 \mathrm{~s}$. They focused on the aromatic formation and they aimed at proposing a small size mechanism (seven groups of compounds are defined). Finally, some global Arrhenius laws can be found to represent the HDPE pyrolysis. They are specifically oriented for hybrid rocket engine but they are based on the regression measures of the solid surface under given operating conditions [4]. As a consequence, they do not allow considering multi-species formation and consumption. The work of Paik and Kar [17] can also be mentioned. They estimated the one step Arrhenius parameters of HDPE pyrolysis as a function of the size of the samples with Thermogravimetric (TG) apparatus. Discrepancies up to $12 \%$ were found.

To the authors' knowledge, no detailed kinetic mechanism considering chemical composition of by-products with limited size suitable for CFD applications (less than 2000 reactions) does exist in open literature. For this reason, the only mechanism to allow computing the pyrolysis products distribution, despite its size, is the one of Németh et al. It is used in the following section to test its validity in comparison with all other available mechanisms and experimental data. 


\section{Computations of HDPE pyrolysis}

127

128

129

130

131

132

133

134

135

136

137

138

139

140

141

142

143

\subsection{Comparison of existing mechanisms from literature}

The work referring to Németh $e t$ al. in this section means that it has been achieved by the present authors with the Németh et al. 's mechanism of HDPE pyrolysis (validated by the Németh et al. at $773 \mathrm{~K}$ ). No modification of the kinetic scheme has been done. It is purely apply in the operating conditions of other existing data to enable a comparison of the validity of all the HDPE pyrolysis studies available in open literature.

\subsubsection{Comparison with Al-Salem and Lettieri experimental data}

Al-Salem and Lettieri conducted experiments with TG balance in which $15 \mathrm{mg}$ samples were heated under undetermined heating rate. Their results are related to solid species, not only HDPE. To make the comparison with Németh et al.'s mechanism data, species products with more than 18 carbon atoms are considered to be in solid phase (Figure 1a). An overall fair agreement is found over the time duration of $600 \mathrm{~s}$ for both temperatures (773 K and $823 \mathrm{~K}$ ). The final solid conversion degree changes from $85 \mathrm{wt} . \%$ at $773 \mathrm{~K}$ to $100 \%$ at $823 \mathrm{~K}$. The fact that a better agreement is found for both mechanisms under long residence time shows that the initial reaction steps probably differ. In addition, numerical computations allow considering instantaneous heating while it is not possible experimentally. This impacts the initial transient behaviour of the data. The timescale to be considered in hybrid propulsion is typically less than $1 \mathrm{~s}$ at elevated temperature, over $1000 \mathrm{~K}$. For this reason, the initial instants are of high importance to represent the dynamics of the phenomena. The disagreement in terms of time, for a given level of solid conversion, will be analysed in section 2.1 .6 to be summarized with other data.

Figure 1 should be placed here.

\subsubsection{Comparison with Johannes et al.' mechanism}

Johannes et al. [16] studied $4 \mathrm{~g}$ HDPE samples pyrolysis in autoclave from $723 \mathrm{~K}$ to $813 \mathrm{~K}$ under steady-state conditions with successive runs at different residence time. These conditions are closer to the numerical simulation assumptions (instantaneous heating) because no heating slope is considered. This is also closer to hybrid rocket conditions. Johannes et al. proposed variable Arrhenius parameters, depending on the temperature, because of the material heating-up process. This correction of kinetic coefficients slows down the pyrolysis process. Their data have been reproduced in the present work with fixed values within an in-house code. The comparison with Németh 
et al.'s data (Figure 1b) shows discrepancies which are stronger with variable coefficients than with fixed ones, particularly for the initial time. The earliest steps of conversion shows a better agreement between Németh et al.'s data and those obtained with fixed coefficient values of Johannes et al.. After a time of $2 \mathrm{~s}$, the discrepancies strongly increase. It can be noticed that it is not clear in the Johannes et al' paper if the autoclave apparatus allows the gas products to go out or if the system is closed. This is important because it impacts the pressure of the system. As a consequence, this may contribute to understand the discrepancies found on Figure $1 \mathrm{~b}$.

\subsubsection{Comparison with Budrugeac's experimental data}

The TG experimental data of Budrugeac [18] have been considered despite low heating rates from 2.99 K.min ${ }^{-1}$ to $12.36 \mathrm{~K} \cdot \mathrm{min}^{-1}$ were used, which do not correspond to hybrid engine $\left(10^{3}\right.$ to $\left.10^{6} \mathrm{~K} \cdot \mathrm{s}^{-1}\right)$. Time delays of almost two hours are found for temperatures between $673 \mathrm{~K}$ and $708 \mathrm{~K}$, before the polymer's pyrolysis starts [18]. The material is not instantaneously heated contrary to numerical simulation. To eliminate this inconsistency, an offset is introduced in all Budrugeac's experimental curves (data are shifted to the left), neglecting the heating-up process (Figure 1c). The kinetics of HDPE pyrolysis is faster at higher temperature. For this reason, the agreement between numerical and experimental results is better at $708 \mathrm{~K}$ than at $673 \mathrm{~K}$. This comparison underlines the difficulty to find appropriate validation data. To the author's knowledge, the only available data on HDPE pyrolysis obtained with flash pyrolysis apparatus are those of Németh et al. while other authors mainly use TG balance. To confirm this point, additional computations have been made by programming numerically the temperature as a function of time (Figure 2). A much better agreement is found compared to isothermal conditions. The transient behaviour from $100 \mathrm{~min}$ to $300 \mathrm{~min}$ for the $673 \mathrm{~K}$ test case (Figure 2a) still differs while at $708 \mathrm{~K}$ (Figure 2b), the dynamics of pyrolysis is better, which is satisfying for high temperature application of the Németh et al.'s mechanism. The errors will be computed and presented in section 2.1.6.

\subsubsection{Comparison with Broadbelt and co-workers' experimental results}

De Witt and Broadbelt [13] carried out low pressure HDPE pyrolysis experiments at $693 \mathrm{~K}$ with different reactant loadings. The species quantification, expressed in molar yield, is given in Table 1. Molar yield is defined by the authors as the number of moles of product divided by the moles of initial reactant charge, which is determined thanks to the molecular weight of HDPE (125000 g. $\left.\mathrm{mol}^{-1}\right)$. Levine and Broadbelt [1], on the basis of De Witt and 
Broadbelt experimental data, proposed a very detailed kinetic mechanism (11000 reactions and 151 species). A conversion of the experimental data, furnished by Broadbelt and co-workers, has been achieved by the present authors to enable comparing them with numerical results (Table 1). A graphical comparison of alkenes (Figure 3a) and alkanes (Figure 3b) distribution shows stronger deviation for low molecular weight species than for heavier ones. The discrepancies are generally lower for alkenes (Figure 3c). For alkenes, the minimal deviation is found for medium molecular weight species. For alkanes distribution, errors are less important for very low molecular weight species, like methane, or for species with more than 20 carbon atoms. It is interesting to observe the ethylene formation because this is one of the major compounds to be produced by HDPE pyrolysis. The experiments of Broadbelt and co-workers show a molar fraction of $7 \mathrm{~mol} \%$ for ethylene after 150 minutes (Figure 3b), while for Németh et al.' mechanism, a stationary phase was already reached after $16.7 \mathrm{~min}$, corresponding to an ethylene content over $20 \mathrm{~mol} . \%$. The deviation between these results remains high. This may be attributed to the dynamics of heating. De Witt and Broadbelt placed a Pyrex ampoule containing HDPE in an isothermal sand bath. The time constants of the system are not given.

Another comparison is proposed for the pyrolysis time at which Németh et al.' kinetic mechanism gives the same ethylene quantity as De Witt and Broadbelt experimental results. The aim is to clarify whether the source of error is related to a time shift or to a chemical reactions set problem. For a time of $433 \mathrm{~s}$, a comparison of alkanes and alkenes distribution is done (see Supplementary materials: Figure 9). Strong discrepancies are still visible and the errors should be compared for the two selected time (after stabilisation at $150 \mathrm{~min}$ and for the same ethylene content at $433 \mathrm{~s}$ ). For alkanes distribution (see Supplementary materials: Figure 9c), the errors are practically the same, and still too high to consider the results as satisfactory. For alkenes distribution (see Supplementary materials: Figure 9d), the deviations between the experimental and numerical results are decreasing for the species with more than 16 atoms of carbon. However, they are much higher for low molecular weight species. A large difference can be found for the 1-pentadecene, for example. Again, these results underline the need for appropriate experimental data, particularly for hybrid rocket application.

Figure 3 should be placed here.

Table 1 should be placed here.

\subsubsection{Comparison with single step Arrhenius law}


Finally, a comparison with the results obtained with one step Arrhenius law is given in Figure 4. The values for the activation energy and the pre-exponential factor from [4] have been obtained at $650 \mathrm{~K}$ with TG measurements $\left(E_{c}=251040 \mathrm{~J} \cdot \mathrm{mol}^{-1}, \mathrm{~A}_{\mathrm{c}}=210^{16} \mathrm{~s}^{-1}, \mathrm{n}=1\right)$. The overall agreement is average. Discrepancies from $30 \%$ and up to several orders of magnitude are found. It is not possible to determine which set of data is correct but, at least, these calculations demonstrate the strong differences which can be obtained between simple Arrhenius laws (which are generally used in hybrid rocket applications) and highly detailed mechanisms. Again, the heating rate may be responsible of these differences. It can be noted that this Arrhenius law has been used at $950 \mathrm{~K}$ by the authors [4] and compared to other experimental data with discrepancies over $50 \%$. In addition, no product formation is proposed with this one step law, which explains why no validation on other species, such as $\mathrm{C}_{2} \mathrm{H}_{4}$, can be proposed.

Figure 4 should be placed here.

\subsubsection{Estimation of time discrepancies during transient pyrolysis}

The discrepancies between Németh' et al.s data and the other ones from literature have been expressed in terms of HDPE or pyrolysis products content. Nevertheless, this is not sufficient since a time shift of two identical curves would not be seen and such case would present disagreement on the chemical composition. Thus, the time for which 80 mol.\% of conversion rate is obtained is determined for all the cases presented above. The relative time error is computed by dividing the time shift between Németh et al. data and the other ones by the highest value of the two (Table 2). A strong disagreement is generally observed. The smallest difference under isothermal conditions is observed with Al-Salem and Lettieri data at $773 \mathrm{~K}$. Due to the wide diversity of experimental conditions and probably of initial HDPE nature, composition and purity (presence of additives), the comparisons of results turn to be highly complicated. For example at $673 \mathrm{~K}$, a time of $19500 \mathrm{~s}$ is found for Budrugeac and $2400 \mathrm{~s}$ for the one step law, based on experiments. The results obtained with Németh et al.' mechanism are in this range (5700 s). This behaviour is due to the heating rate. Indeed, a minimum error is obtained for Budrugeac comparison with timefunction programming of the temperature. When the experimental conditions are thus better reproduced numerically, the Németh et al.'s mechanism is found to be of fair agreement with experimental results. This tends to confirm the validity of Németh et al.' mechanism despite additional validation should be done with appropriate experimental data in order to guarantee the mechanism's validity and its suitability for the range to be considered in hybrid rocket. 


\subsection{Further analysis of the Németh et al. mechanism}

In order to conduct combustion study to determine auto-ignition delays, it is required to have a pyrolysis scheme which is able to fairly predict the consumption of HDPE and the production of the main gas products (ethylene, methane, ethane,...). In addition, this mechanism should be compatible with CFD applications. The one of Dagaut and Cathonnet [19] is expected to be used in the CFD code (size of 1592 reactions and 207 species). The Németh $e t$ al.'s mechanism is the only available mechanism to answer to the first criterion. It may answer the second one if 1-D simulations are conducted but it needs to be reduced for 2-D computations. The reduction of detailed kinetic mechanism is a complex work and before doing it, it must be verified that the initial mechanism is well suited for the application. For this reason, the above section 2.1 aimed at investigating the validity of the scheme, without clearly demonstrating it due to the lack of suitable validation data in open literature. Thus, it is decided to conduct an additional work on the behaviour of the mechanism in operating conditions close to those expected for hybrid propulsion. This work is presented in the present section 2.2.

A brief parametric study on pressure and temperature effects is achieved to observe the results on HDPE consumption and on ethylene production. For each thermal plateau (700 K, $1200 \mathrm{~K}$ and $1700 \mathrm{~K})$, the pressure is varied from 1 bar to 100 bar (under isobaric conditions). The time for which $80 \mathrm{~mol} \%$ of conversion rate is obtained is determined. An intrinsic limit of the homogeneous kinetic scheme is finally presented.

\subsubsection{Parametric study}

The transient variations of molar fraction under different pressure and temperature conditions are shown in Figure 5 at $700 \mathrm{~K}$ (see Supplementary materials Figure 10 for $1200 \mathrm{~K}$ ). At $700 \mathrm{~K}$ (Figure 5), the pressure slows the pyrolysis process and it reduces the amount of ethylene content (from $32 \mathrm{~mol} \%$ at 1 bar to $10 \mathrm{~mol} . \%$ at $100 \mathrm{bar}$ ). It has a lighter effect on HDPE consumption. The pyrolysis times are very high, over $15 \mathrm{~min}$, and they are not compatible with the conditions to be encountered on hybrid rocket engine (residence time of oxidiser flow less than $1 \mathrm{~s}$ [4]). At $1200 \mathrm{~K}$ (see Supplementary materials: Figure 10), the pyrolysis time is strongly reduced to the order of millisecond. This time is in conformity with the dynamics of phenomena involved in hybrid rocket [7]. Nevertheless, this temperature is outside the range of experimental validation proposed by Németh et al. [12]. The kinetic mechanism accuracy is not guaranteed. Increasing the pressure at $1200 \mathrm{~K}$ slows down the ethylene production but in a very slight way (from 45 mol.\% to 40 mol.\% at 1 bar and 100 bar respectively). Additional 
computations at $1700 \mathrm{~K}$ have shown characteristic pyrolysis time of the order of the nanosecond, which is questionable. This behaviour is due to the exponential form of Arrhenius law which is enhanced by the temperature. The Németh et al.' mechanism probably reaches its limit of validity over $1200 \mathrm{~K}$.

\section{Figure 5 should be placed here.}

The pressure effect which is clear at $700 \mathrm{~K}$ (Figure 5), tends to get negligible at $1200 \mathrm{~K}$ in the range $1 \mathrm{bar}-$ 34 bar and it could be omitted as a first approximation (Figure 6a). This is mainly acceptable for stabilised conditions (after $2 \mathrm{~ms}$ ) but for transient state (from initial time to $2 \mathrm{~ms}$ ), the pressure has a greater impact. The coupled effect of temperature and pressure can be observed for ethylene which formation is important in terms of combustion. For a fixed pressure value between two temperatures (Figure $6 b$ ) the higher the pressure, the more important the curve's slope. That means that the effect of temperature increase is stronger for high pressure. The pyrolysis times related to a HDPE conversion rate of $80 \mathrm{~mol} . \%$ are summarized in Table 3 . The temperature rise accelerates the pyrolysis phenomenon. For fixed temperature, high pressures favour HDPE consumption except for some conditions, like $700 \mathrm{~K}$ and over 10 bar for example. This is clearly visible on Figure $7 \mathrm{a}$ where low temperature conditions present a minimum of pyrolysis time versus the pressure. This minimum depends on the pressure and the corresponding pressure can be plotted as a function of the temperature (Figure 7b). The exponential trend highlights the difficulty to find a pressure at temperature over $900 \mathrm{~K}$, for which the pyrolysis time would be minimum. This specific behaviour is further detailed in next section since the pressure effect is more complex than only impacting the concentration of gas species and thus enhancing the molecular collisions.

Figure 6 should be placed here.

Table 3 should be placed here.

Figure 7 should be placed here.

\subsubsection{Limit of the mechanism used in a 0-D closed vessel}

The pyrolysis calculations are achieved in this study under 0-D configuration. The perfect gases law is used to determine the density, which is of importance in energy equation and in the calculation of species concentrations. If the chemical products are not produced in gas phase, the resulting error is not negligible. For example, the HDPE density is $950 \mathrm{~kg} \cdot \mathrm{m}^{-3}$ but at $700 \mathrm{~K}$ and $1 \mathrm{bar}$, the value of $9.673 \mathrm{~kg} \cdot \mathrm{m}^{-3}$ is computed. This is not realistic and it can be 
corrected by choosing an artificially high pressure (approximately 100 times more), as it is done by Nemeth et al. The drawback of such method is that it would also impact the gas phase. Then, the pressure effect would not properly be taken into account. As a consequence, it must be determined when the solid content is higher than the gas content. If the first is higher than the second, an artificial pressure should be considered. To the opposite, no artificial pressure should be considered if the gaseous compounds are the major products. This would allow suitably addressing the chemistry in gas phase.

For two different pressures and for temperatures from $700 \mathrm{~K}$ to $1700 \mathrm{~K}$, the yields of solid and of gaseous compounds have been computed to determine which method should be considered (Figure 8a). For temperatures under $850 \mathrm{~K}$ at 1 bar and under $1000 \mathrm{~K}$ at $34 \mathrm{bar}$, the solid species content is higher than the gas one. Consequently, for these cases, the pressure should be increased strongly to simulate the right polymer density (Figure $8 \mathrm{~b}$ ). The error which is due to the pressure setting can be observed by comparing Figure 5a and Figure 5d since the temperature is lower than $850 \mathrm{~K}$. A factor 3 is found on the ethylene formation and a strong time delay is also remarkable. This highlights the difficulty of considering single phase computations. Nevertheless, this will be corrected in future work because this mechanism will be implemented in a 2-D geometry considering both solid and gas phases with appropriate description.

Figure 8 should be placed here.

By fixing the pressure at 112 bar and the temperature at $773 \mathrm{~K}$, the polymer density is $950 \mathrm{~kg} \cdot \mathrm{m}^{-3}$. The comparison of these results with those from Németh et al.' experiments, for the same temperature and residence time, gives fortunately a very good agreement (see Supplementary materials: Figure 11).

\section{Conclusion}

A strong lack of chemical kinetic mechanisms and of experimental data has been found in actual bibliography for polyethylene pyrolysis. The rare data must be carefully considered before applying them to propulsion application since they are generally obtained for polymer's recycling purpose. The temperature and pressure levels and the heating rate differ up to several orders of magnitude. As a consequence, a comparative work has been achieved in this paper to determine the consistency of existing works. Only six studies with single step or multi-step mechanisms have been found. They have been compared with the most detailed mechanism to determine their respective efficiency. Up to $85 \%$ of time shift has been found. A factor 7 is even found between two experimentally 
based works. This is due to the test conditions, to the heating rate and to the apparatus which differ between these studies. Due to the wide diversity of experimental conditions and initial HDPE nature, comparing these mechanisms turns to be highly complicated. The conclusion of this comparative work is that further experiments in conditions of use are necessary to get reliable data for correcting existing mechanisms. A parametric study has been achieved on temperature, time and pressure effect with the most detailed kinetic scheme to observe its strength and weak points, particularly for hybrid rocket application. The high temperature range (over $1200 \mathrm{~K}$ ) is probably not appropriate.

Nevertheless, the most detailed mechanism is the only one to quantify the gas products by identifying the different species instead of using a global approach with a single gas compound. This fine description is compulsory for a later step to conduct a combustion study aiming at determining the auto-ignition delays of the pyrolysis products. A two dimensions numerical code is under development to combine both pyrolysis and combustion studies in a hybrid combustor. The existing detailed kinetic mechanism must now be reduced to an acceptable size for Computational Fluid Dynamics simulation (less than 2000 reactions and 300 species instead of 7541 reactions and 1014 species presently). This work is presented in a companion paper [14]. Only later, experimental work will be achieved to get reliable data and to correct the reduced mechanism, which should be easier to handle than the original one.

\section{Acknowledgements}

The authors would like to acknowledge the Roxel company for its financial support.

\section{References}

[1] S. E. Levine and L. J. Broadbelt, Detailed mechanistic modelling of HDPE pyrolysis: Low molecular weight product evolution, Polymer Degradation and Stability 94 (2009) 810-822

[2] S.M. Al-Salem and P. Lettieri, Kinetic study of high density polyethylene (HDPE) pyrolysis, Polymer chemical engineering research and design 88 (2010) 1599-1606

[3] R.W.J. Westerhout, J. Waanders, W.P.M. Van Swaaij, Recycling of polyethene and polypropene in a novel bench-scale rotating cone reactor by high-temperature pyrolysis, Ind. Eng. Chem. Res. 37 (6) (1998) $2293-$ 2300

[4] M. J. Chiaverini and K. K. Kuo, Fundamentals of hybrid rocket combustion and propulsion, Volume 218, Published by the American Institute of Aeronautics and Astronautics, Reston, Virginia

[5] M. D. Wallis and Suresh K. Bhatia, Thermal degradation of high density polyethylene in a reactive extruder, Polymer Degradation and Stability 92 (2007) 1721-1729

[6] A. Aboulkas, K. El harfi, A. El Bouadili, Thermal degradation behaviors of polyethylene and polypropylene. Part I: Pyrolysis kinetics and mechanisms, Thermochimica Acta 500 (2010) 30-37

[7] N. Gascoin and P. Gillard, Preliminary pyrolysis and combustion study for the hybrid propulsion, 46th AIAA/ASME/SAE/ASEE Joint Propulsion Conference \& Exhibit, 25-28 Jul 2010, Nashville, AIAA-20106871.

[8] J.F. Mastral, C. Berrueco, J. Ceamanos, Modelling of the pyrolysis of high density polyethylene Product distribution in a fluidized bed reactor, J. Anal. Appl. Pyrolysis 79 (2007) 313-322 
[9] M.L. Poutsma, Reexamination of the Pyrolysis of Polyethylene: Data Needs, Free-Radical Mechanistic Considerations, and Thermochemical Kinetic Simulation of Initial Product-Forming Pathways, Macromolecules 2003, 36, 8931-8957

[10] T. P. Wampler, Applied Pyrolysis Handbook, 2007 Taylor \& Francis Group LLC

[11] M.L. Poutsma, Fundamental reactions of free radicals relevant to pyrolysis reactions, Journal of Analytical and Applied Pyrolysis, 54 (2000) 5-35

[12] A. Németh, M. Blazso, P. Baranyai, T. Vidoczy, Thermal degradation of polyethylene modelled on tetracontane, J. Anal. Appl. Pyrolysis 81 (2008) 237-242

[13] M. J. De Witt and L. J. Broadbelt, Binary Interactions between High-Density Polyethylene and 4-(1Naphthylmethyl)bibenzyl during Low-Pressure, Energy \& Fuels 2000, 14, 448-458

[14] N. Gascoin, A. Navarro-Rodriguez, G. Fau, P.Gillard, Kinetic Modelling of High Density PolyEthylene Pyrolysis: Part 2. Reduction of existing detailed mechanism, 10.1016/j.polymdegradstab.2012.04.002

[15] G. Elordi, G. Lopez, M. Olazar, R. Aguado, J. Bilbao, Product distribution modelling in the thermal pyrolysis of high density polyethylene, Journal of Hazardous Materials 144 (2007) 708-714

[16] I. Johannes, H. Tamvelius, L. Tiikma, A step-by-step model for pyrolysis kinetics of polyethylene in an autoclave under non-linear increase of temperature, J. Anal. Appl. Pyrolysis 72 (2004) 113-119

[17] P. Paik and K. K. Kar, Thermal degradation kinetics and estimation of lifetime of polyethylene particles: effects of particle size, Materials Chemisty and Physics 113 (2009) 953-961

[18] P. Budrugeac, Theory and practice in the thermoanalytical kinetics of complex processes: application for the isothermal and non-isothermal degradation of HDPE, 2009, Thermochimica Acta 500 (2010) 30-37

[19] P. Dagaut and M. Cathonnet, The ignition, oxidation, and combustion of kerosene: A review of experimental and kinetic modeling, Progress in Energy and Combustion Science, Volume 32, Issue 1, 2006, pp. 48-92. 
Figure 1. Comparison of computations with Németh et al. mechanism with experiments of Al-Salem and Lettieri (a), of Johannes et al. (b) and of Budrugeac (c).

Figure 2 Comparison between Budrugeac's experimental results at $673 \mathrm{~K}$ (a) and $708 \mathrm{~K}$ (b) with time-function results obtained with Németh $e t$ al.'s mechanism.

Figure 3 Comparison of computations with Broadbelt and coworkers' experimental results [13] after 150 minutes of pyrolysis at $693 \mathrm{~K}$ for alkanes (a) and alkenes distribution (b) and corresponding error distributions (c).

Figure 4 Comparison of detailed kinetic mechanism numerical results ( - ) with one step Arrhenius law ( $\cdots$ ) at $650 \mathrm{~K}$ (a) and $673 \mathrm{~K}(\mathrm{~b})$.

Figure 5. HDPE consumption and $\mathrm{C}_{2} \mathrm{H}_{4}$ production at $700 \mathrm{~K}$ and $1 \mathrm{bar}(\mathrm{a}), 10 \mathrm{bar}(\mathrm{b}), 34 \mathrm{bar}(\mathrm{c}), 100 \mathrm{bar}(\mathrm{d})$

Figure 6 Pressure influence (1 bar, 10 bar, 34 bar) on HDPE consumption and $\mathrm{C} 2 \mathrm{H} 4$ production for different temperature values: $1200 \mathrm{~K}$ (a) and Influence of temperature in $\mathrm{C} 2 \mathrm{H} 4$ production for different pressure values (b)

Figure 7 Evolution of pyrolysis time with pressure and temperature increase (a) and temperature-pressure coordinates of the minimum of pyrolysis time (b)

Figure 8 Gas and solid content during HDPE pyrolysis (a) and domain of applicability of the Németh et al. mechanism (b).

Table 1. Identification and quantification of HDPE thermal degradation products [13] at low pressure and $693 \mathrm{~K}$ after 150 minutes of pyrolysis. Comparison with numerical results of Németh et al.' mechanism.

Table 2. Relative errors found when comparing data with those from Németh et al.' mechanism.

Table 3 Pyrolysis time for different operating conditions.

\section{SUPPLEMENTARY MATERIAL}

Figure 9 Comparison between computations after $493 \mathrm{~s}$ of pyrolysis and Broadbelt and coworkers' experimental results [13] after 150 minutes of pyrolysis for the same ethylene production during HDPE pyrolysis at $693 \mathrm{~K}$ : alkanes (a), alkenes (b), corresponding errors on alkanes (c) and on alkenes (d).

Figure 10. HDPE consumption and $\mathrm{C}_{2} \mathrm{H}_{4}$ production at $1200 \mathrm{~K}$ and 1 bar (a), 10 bar (b), 34 bar (c), 100 bar (d)

Figure 11 Comparison between Németh et al.' experimental products distribution data (at 1 bar) and numerical results (at 112 bar) at $773 \mathrm{~K}$ and $20 \mathrm{~s}$ of reaction time for gaseous alkanes (a) and alkenes (b) and for non gaseous alkanes (c) and alkenes (d). 
409
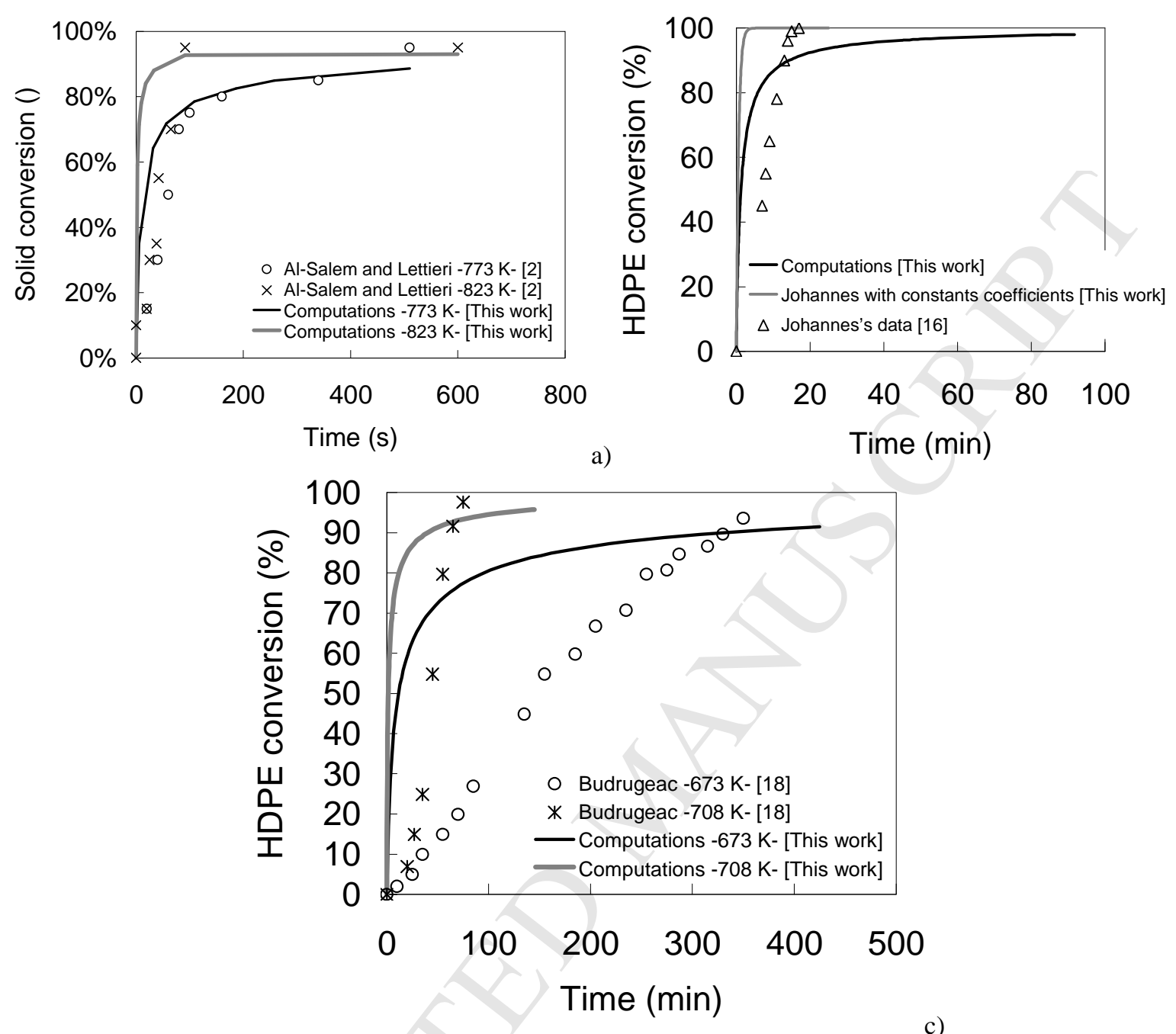

411

Figure 1. Comparison of computations with Németh et al. mechanism with experiments of Al-Salem and 

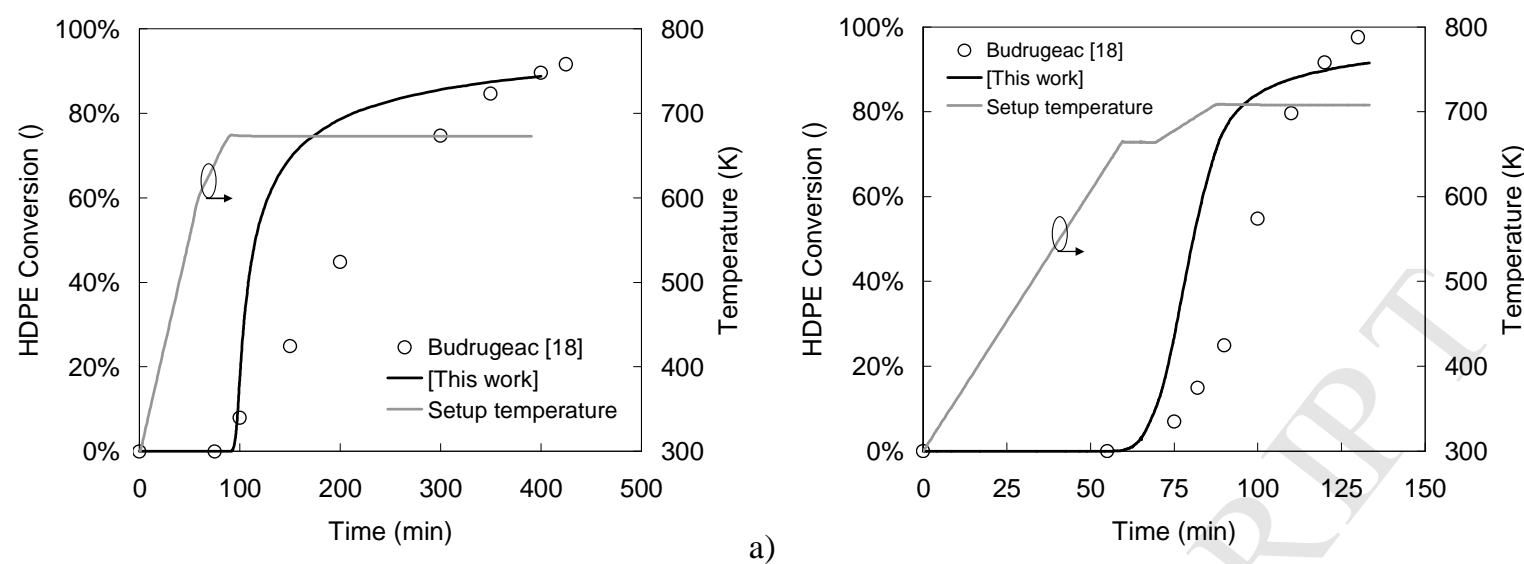

b)

Figure 2 Comparison between Budrugeac's experimental results at $673 \mathrm{~K}$ (a) and $708 \mathrm{~K}$ (b) with timefunction results obtained with Németh et al.'s mechanism. 

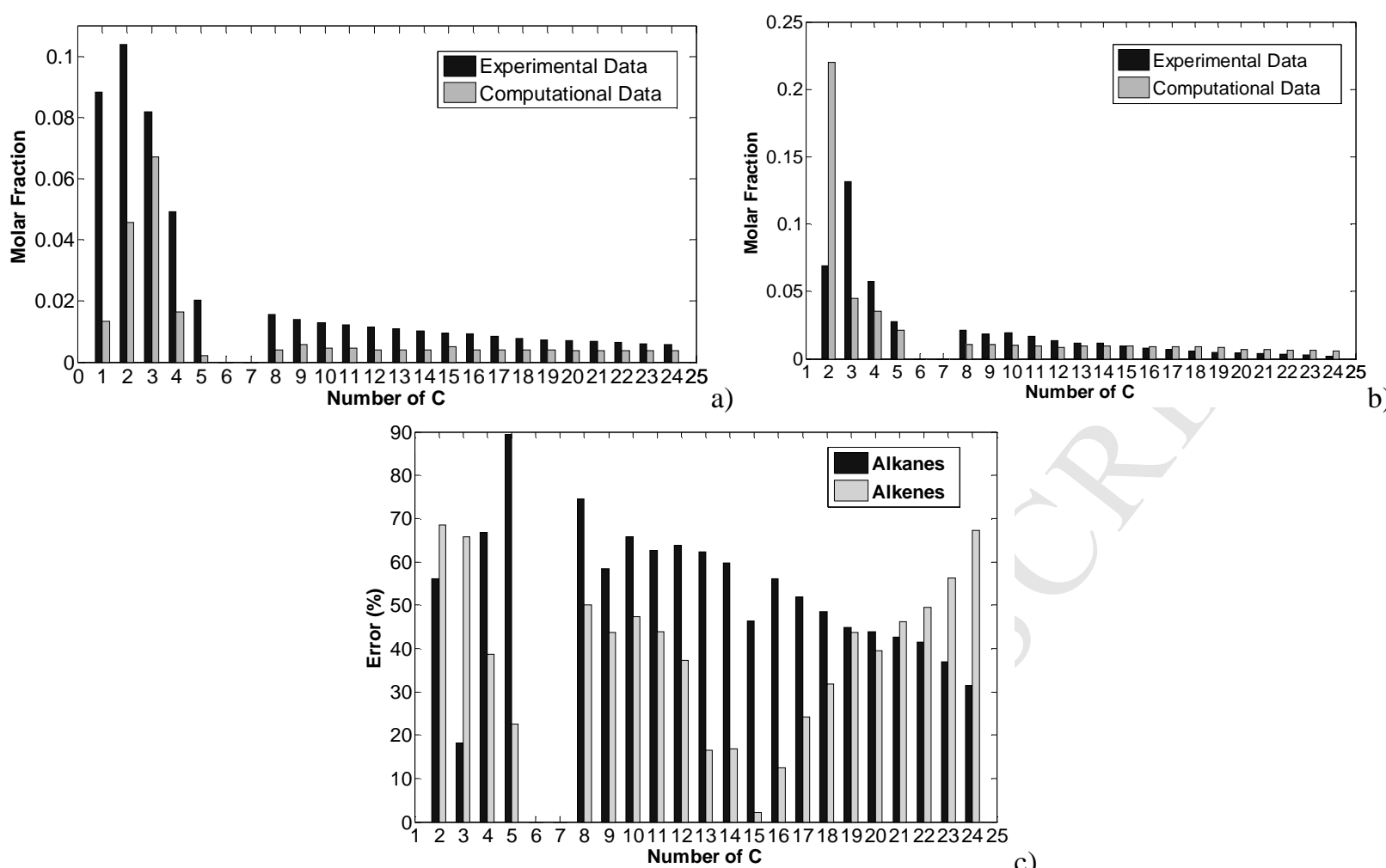

Figure 3 Comparison of computations with Broadbelt and coworkers' experimental results [13] after 150 minutes of pyrolysis at $693 \mathrm{~K}$ for alkanes (a) and alkenes distribution (b) and corresponding error 

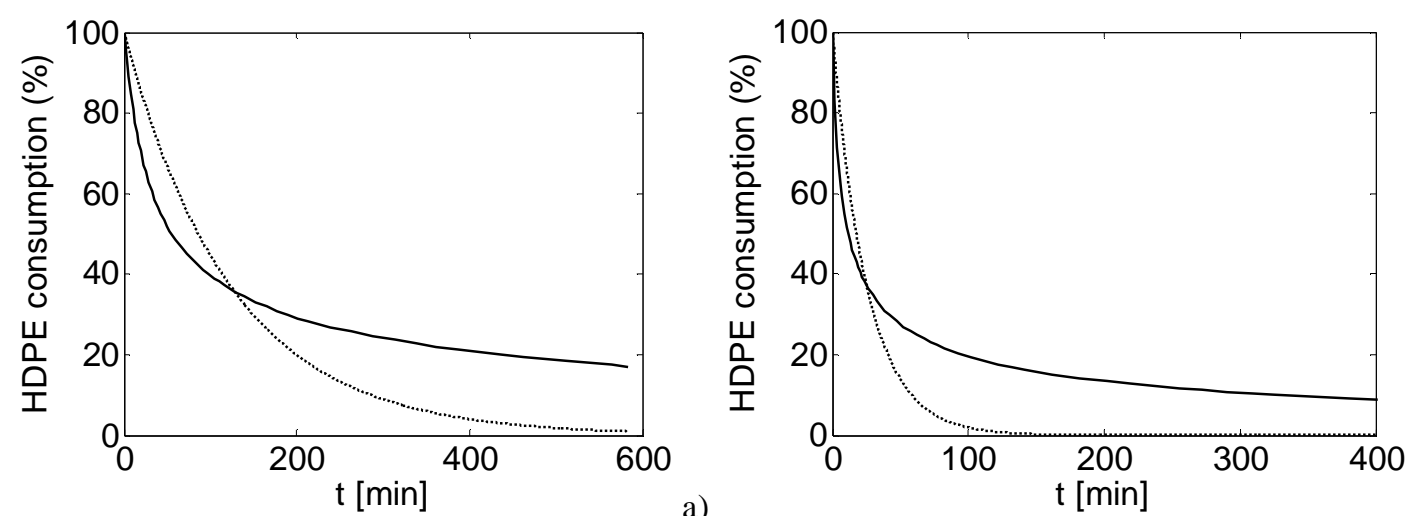

b)

Figure 4 Comparison of detailed kinetic mechanism numerical results ( - ) with one step Arrhenius law ( $\cdots$ ) at $650 \mathrm{~K}$ (a) and $673 \mathrm{~K}(\mathrm{~b})$. 
426
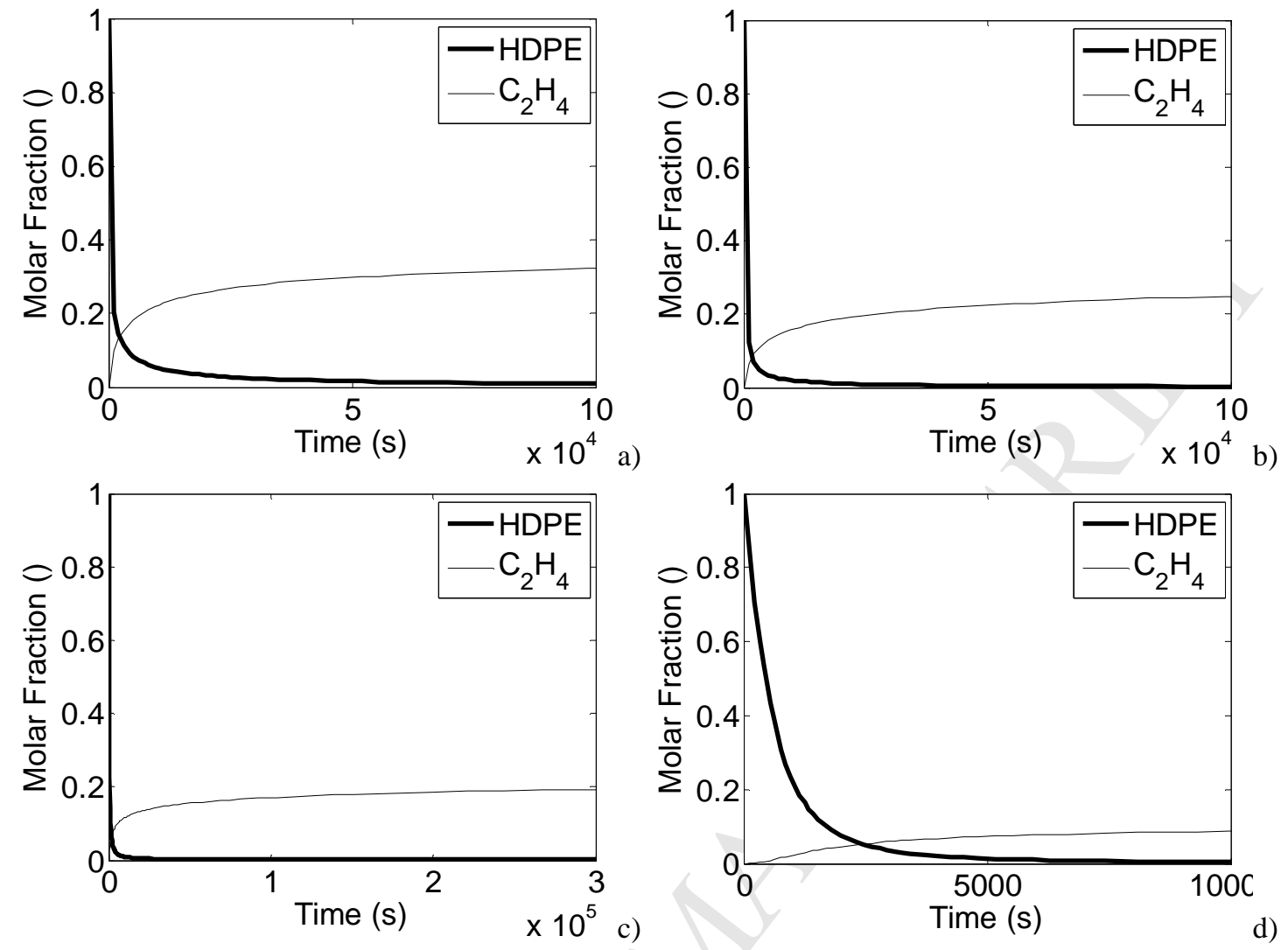

Figure 5. HDPE consumption and $\mathrm{C}_{2} \mathrm{H}_{4}$ production at $700 \mathrm{~K}$ and $1 \mathrm{bar}(\mathrm{a}), 10 \mathrm{bar}(\mathrm{b}), 34 \mathrm{bar}(\mathrm{c}), 100 \mathrm{bar}(\mathrm{d})$ 

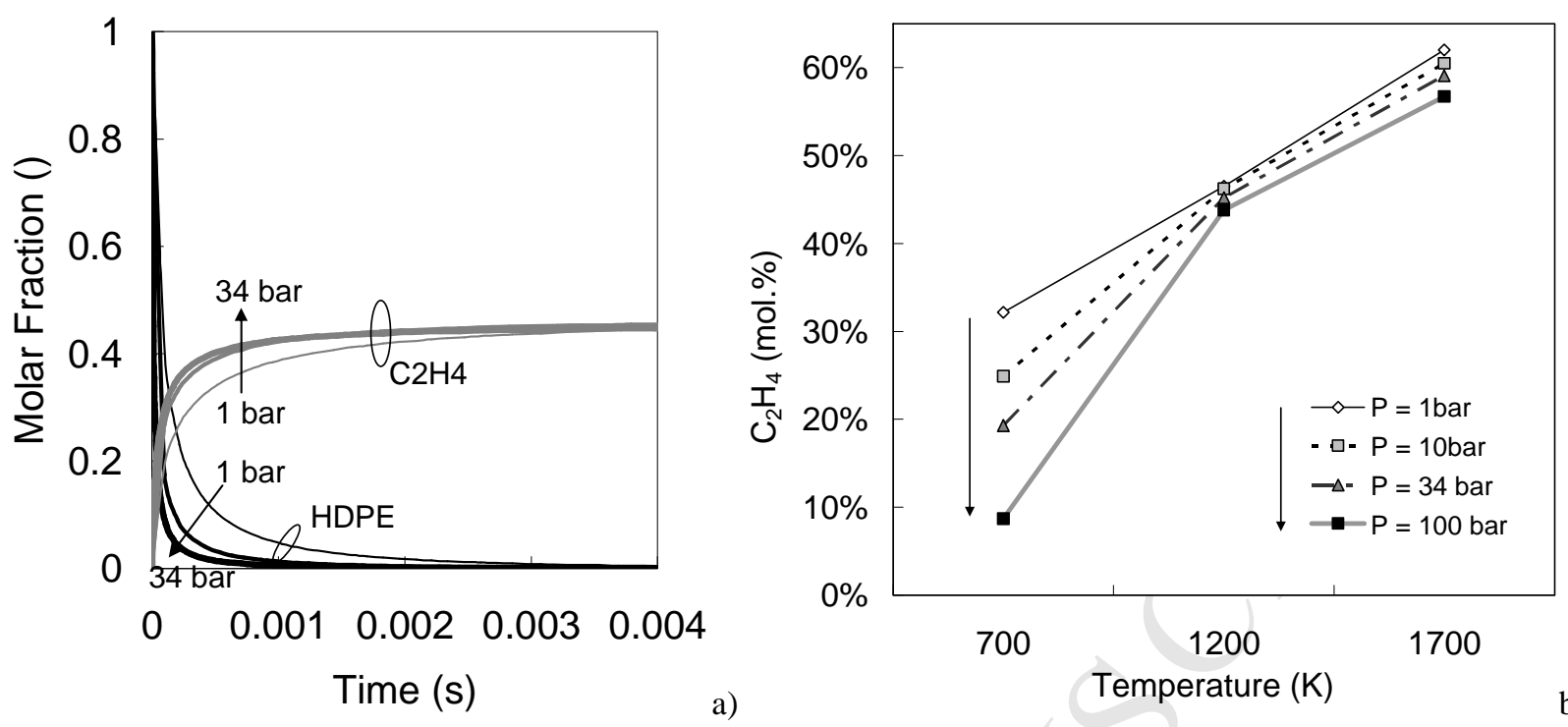

Figure 6 Pressure influence ( 1 bar, 10 bar, 34 bar) on $\mathrm{HDPE}$ consumption and $\mathrm{C}_{2} \mathrm{H}_{4}$ production for different temperature values: $1200 \mathrm{~K}$ (a) and Influence of temperature in $\mathrm{C}_{2} \mathrm{H}_{4}$ production for different pressure values 
434

435

436

437
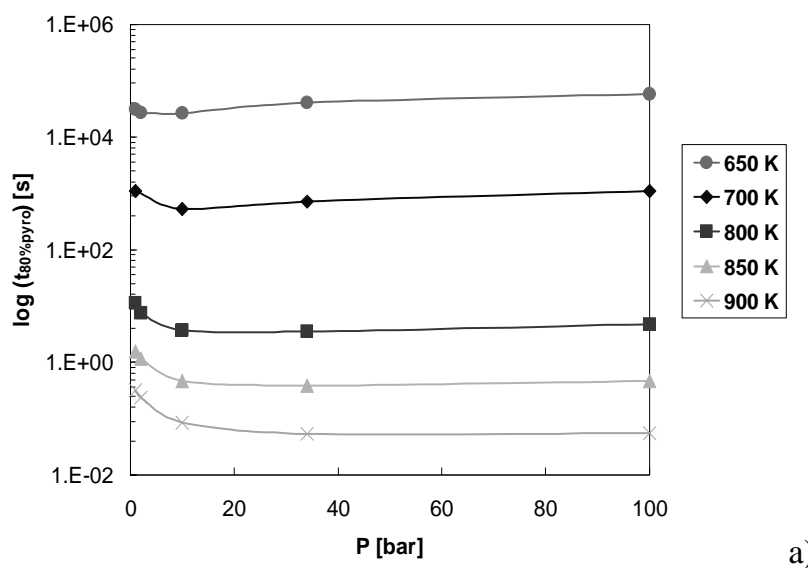

Figure 7 Evolution of pyrolysis time with pressure and temperature increase (a) and temperature-pressure coordinates of the minimum of pyrolysis time $(b)$ 
438

439

440

441

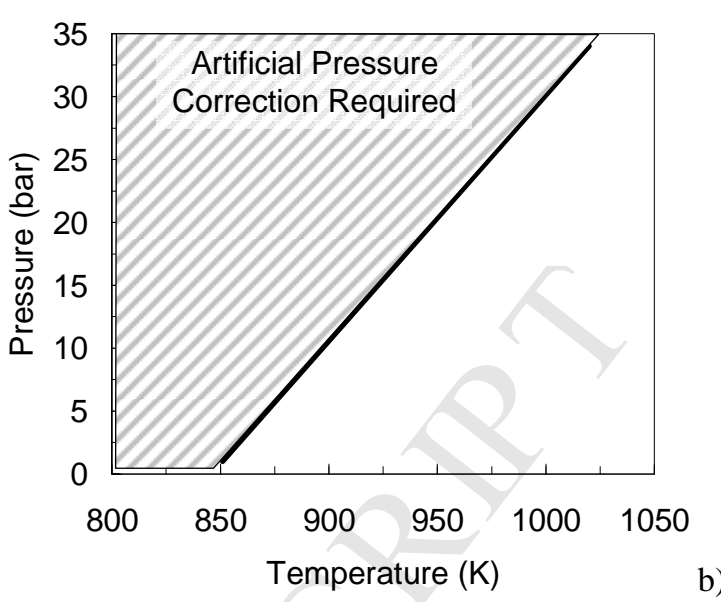

b)

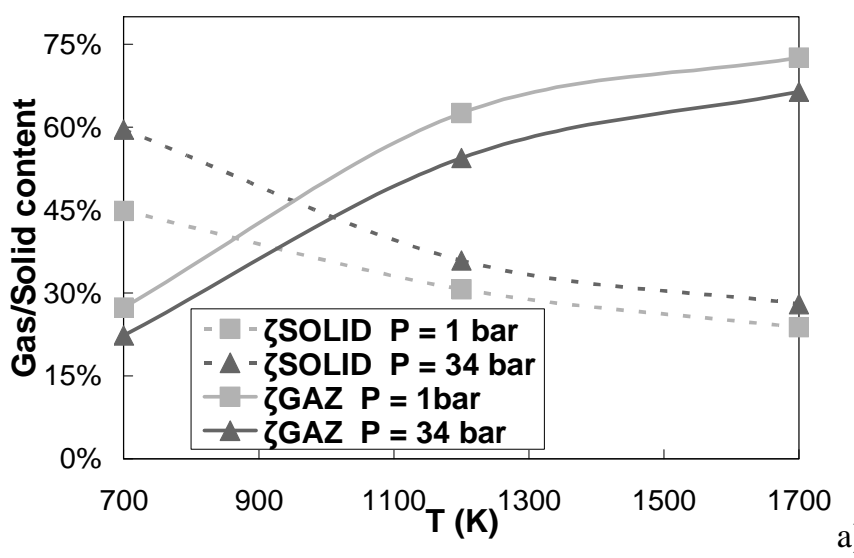
mechanism (b). 
443 Table 1. Identification and quantification of HDPE thermal degradation products [13] at low pressure and $444693 \mathrm{~K}$ after 150 minutes of pyrolysis. Comparison with numerical results of Németh et al.' mechanism.

\begin{tabular}{|c|c|c|c|}
\hline & $\begin{array}{c}\text { Normalized } \\
\text { Yield [25] }\end{array}$ & $\begin{array}{l}\text { Corresponding } \\
\text { Molar Fraction }\end{array}$ & $\begin{array}{l}\text { Computed Molar Fraction } \\
\text { with Nemeth's mech. }\end{array}$ \\
\hline methane & 35.46 & 0.088 & 0.013 \\
\hline ethylene & 27.83 & 0.069 & 0.220 \\
\hline ethane & 41.71 & 0.104 & 0.046 \\
\hline propylene & 52.72 & 0.132 & 0.045 \\
\hline propane & 32.86 & 0.082 & 0.067 \\
\hline 1-butene & 23.09 & 0.058 & 0.035 \\
\hline n-butane & 19.75 & 0.049 & 0.016 \\
\hline 1-pentene & 11.08 & 0.028 & 0.021 \\
\hline n-pentane & 8.15 & 0.020 & 0.002 \\
\hline 1-octene & 8.51 & 0.021 & 0.011 \\
\hline n-octane & 6.24 & 0.016 & 0.004 \\
\hline 1-nonene & 7.41 & 0.018 & 0.010 \\
\hline n-nonane & 5.55 & 0.014 & 0.006 \\
\hline 1-decene & 7.77 & 0.019 & 0.010 \\
\hline n-decane & 5.24 & 0.013 & 0.004 \\
\hline 1-undecene & 6.64 & 0.017 & 0.009 \\
\hline n-undecane & 4.94 & 0.012 & 0.005 \\
\hline 1-dodecene & 5.53 & 0.014 & 0.009 \\
\hline n-dodecane & 4.62 & 0.012 & 0.004 \\
\hline 1-tridecene & 4.68 & 0.012 & 0.010 \\
\hline n-tridecane & 4.4 & 0.011 & 0.004 \\
\hline 1-tetradecene & 4.62 & 0.012 & 0.010 \\
\hline n-tetradecane & 4.09 & 0.010 & 0.004 \\
\hline 1-pentadecene & 3.85 & 0.010 & 0.009 \\
\hline n-pentadecane & 3.85 & 0.010 & 0.005 \\
\hline 1-hexadecene & 3.23 & 0.008 & 0.009 \\
\hline n-hexadecane & 3.73 & 0.009 & 0.004 \\
\hline 1-heptadecene & 2.76 & 0.007 & 0.009 \\
\hline n-heptadecane & 3.39 & 0.008 & 0.004 \\
\hline 1-octadecene & 2.41 & 0.006 & 0.009 \\
\hline n-octadecane & 3.15 & 0.008 & 0.004 \\
\hline 1-nonadecene & 1.95 & 0.005 & 0.009 \\
\hline n-nonadecane & 2.9 & 0.007 & 0.004 \\
\hline 1-eicosene & 1.73 & 0.004 & 0.007 \\
\hline n-eicosane & 2.8 & 0.007 & 0.004 \\
\hline 1-heneicosene & 1.49 & 0.004 & 0.007 \\
\hline n-heneicosane & 2.72 & 0.007 & 0.004 \\
\hline 1-docosene & 1.34 & 0.003 & 0.007 \\
\hline n-docosane & 2.65 & 0.007 & 0.004 \\
\hline 1-tricosene & 1.11 & 0.003 & 0.006 \\
\hline n-tricosane & 2.47 & 0.006 & 0.004 \\
\hline 1-tetracosene & 0.8 & 0.002 & 0.006 \\
\hline n-tetracosane & 2.28 & 0.006 & 0.004 \\
\hline
\end{tabular}


Table 2. Relative errors found when comparing data with those from Németh et al.' mechanism.

\begin{tabular}{|c|c|c|c|c|c|}
\hline & & Temperature & $\mathbf{t}_{\mathbf{8 0} \% \text { Németh }}(\mathbf{s})$ & $\mathbf{t}_{80 \% \text { other }}(\mathbf{s})$ & Relative Time Error \\
\hline \multirow{2}{*}{\multicolumn{2}{|c|}{ Al-Salem and Lettieri ${ }^{*}$}} & $773 \mathrm{~K}$ & 83 & 160 & $48.25 \%$ \\
\hline & & $823 \mathrm{~K}$ & 8 & 82 & $89.95 \%$ \\
\hline \multirow{4}{*}{ Budrugeac } & \multirow{2}{*}{ Isothermal } & $673 \mathrm{~K}$ & 5700 & 19500 & $70.76 \%$ \\
\hline & & $708 \mathrm{~K}$ & 720 & 6616 & $89.12 \%$ \\
\hline & \multirow{2}{*}{$\begin{array}{l}\text { Time- } \\
\text { function }\end{array}$} & $673 \mathrm{~K}$ & 22971 & 19500 & $15.11 \%$ \\
\hline & & $708 \mathrm{~K}$ & 5645 & 6616 & $14.68 \%$ \\
\hline \multirow{2}{*}{\multicolumn{2}{|c|}{ Johannes et al. }} & $773 \mathrm{~K}$ & 348 & $60\left(\mathrm{k}_{\mathrm{i}}\right.$ cte $)$ & $-82.18 \%$ \\
\hline & & & & 675 ( $\mathrm{k}_{\mathrm{i}}$ var) & $-48.44 \%$ \\
\hline \multirow{2}{*}{\multicolumn{2}{|c|}{ One step Arrhenius law }} & $650 \mathrm{~K}$ & 25800 & 12000 & $53.48 \%$ \\
\hline & & $673 \mathrm{~K}$ & 5700 & 2400 & $57.90 \%$ \\
\hline
\end{tabular}


Table 3 Pyrolysis time for different operating conditions.

\begin{tabular}{cccccccc}
\hline \hline & $\mathbf{6 5 0} \mathbf{K}$ & $\mathbf{7 0 0 ~ K}$ & $\mathbf{8 0 0 ~ K}$ & $\mathbf{8 5 0 ~ K}$ & $\mathbf{9 0 0 ~ K}$ & $\mathbf{1 2 0 0 ~ K}$ & $\mathbf{1 7 0 0 ~ K}$ \\
\hline $\mathbf{1}$ bar & $3,12 \cdot 10^{4} \mathrm{~s}$ & $1090 \mathrm{~s}$ & $11,1 \mathrm{~s}$ & $1,57 \mathrm{~s}$ & $3,19 \cdot 10^{-1} \mathrm{~s}$ & $2,46 \cdot 10^{-4} \mathrm{~s}$ & $8,16 \cdot 10^{-8} \mathrm{~s}$ \\
$\mathbf{2}$ bar & $2,68 \cdot 10^{4} \mathrm{~s}$ & --- & $7,33 \mathrm{~s}$ & $1,15 \mathrm{~s}$ & $2,35 \cdot 10^{-1} \mathrm{~s}$ & -- & -- \\
$\mathbf{1 0}$ bar & $2,59 \cdot 10^{4} \mathrm{~s}$ & $523 \mathrm{~s}$ & $3,72 \mathrm{~s}$ & $4,65 \cdot 10^{-1} \mathrm{~s}$ & $8,42 \cdot 10^{-2} \mathrm{~s}$ & $8,54 \cdot 10^{-5} \mathrm{~s}$ & $6,5 \cdot 10^{-8} \mathrm{~s}$ \\
$\mathbf{3 4} \mathbf{b a r}$ & $4,05 \cdot 10^{4} \mathrm{~s}$ & $716 \mathrm{~s}$ & $3,49 \mathrm{~s}$ & $3,77 \cdot 10^{-1} \mathrm{~s}$ & $5,31 \cdot 10^{-2} \mathrm{~s}$ & $3,9 \cdot 10^{-5} \mathrm{~s}$ & $4,94 \cdot 10^{-8} \mathrm{~s}$ \\
$\mathbf{1 0 0}$ bar & $5,73 \cdot 10^{4} \mathrm{~s}$ & $1090 \mathrm{~s}$ & $4,70 \mathrm{~s}$ & $4,65 \cdot 10^{-1} \mathrm{~s}$ & $5,44 \cdot 10^{-2} \mathrm{~s}$ & $1,96 \cdot 10^{-5} \mathrm{~s}$ & $3,41 \cdot 10^{-8} \mathrm{~s}$ \\
\hline \hline
\end{tabular}



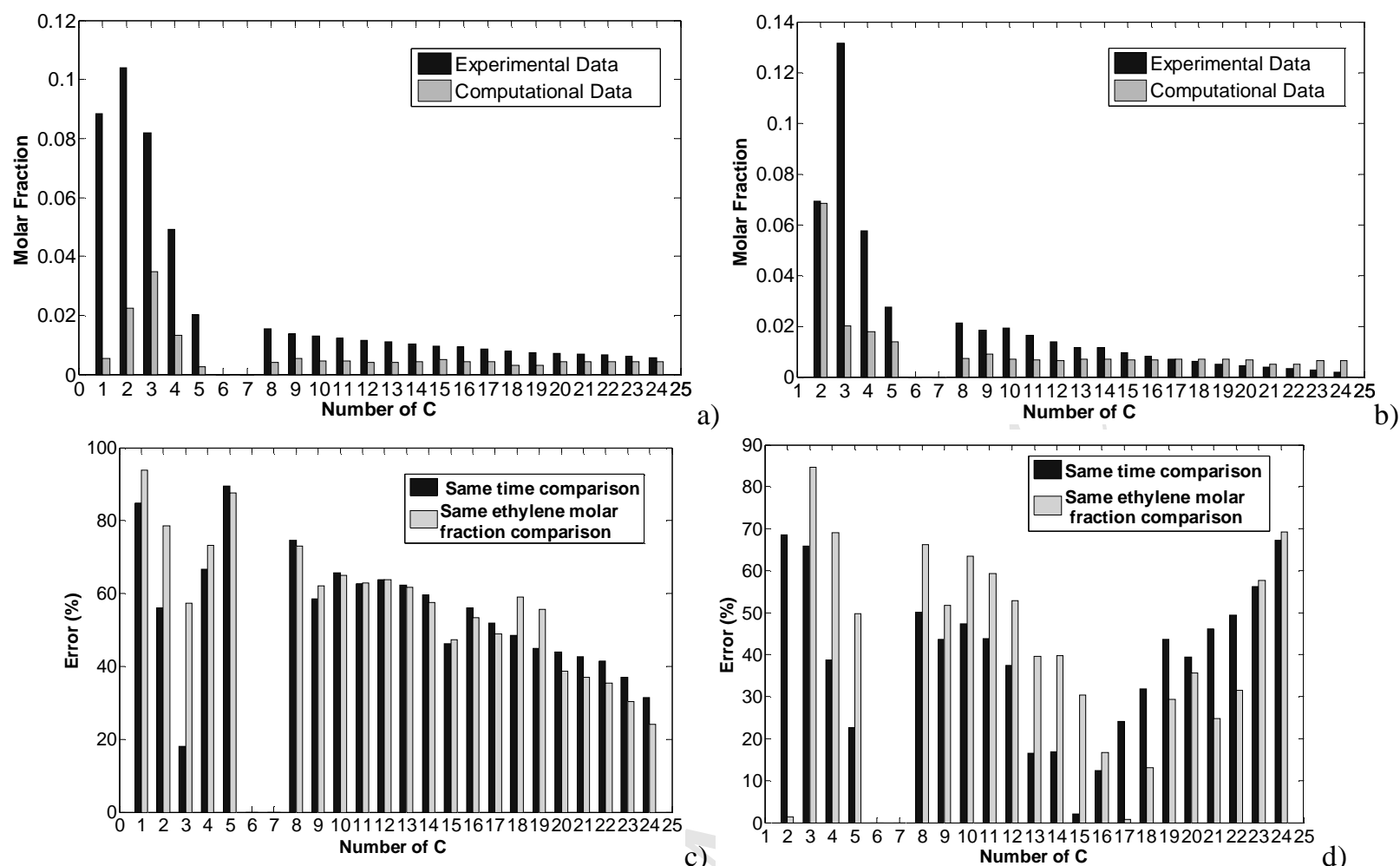

b)

Figure 9 Comparison between computations after $493 \mathrm{~s}$ of pyrolysis and Broadbelt and coworkers' experimental results [13] after 150 minutes of pyrolysis for the same ethylene production during HDPE pyrolysis at $693 \mathrm{~K}$ : alkanes (a), alkenes (b), corresponding errors on alkanes (c) and on alkenes (d). 

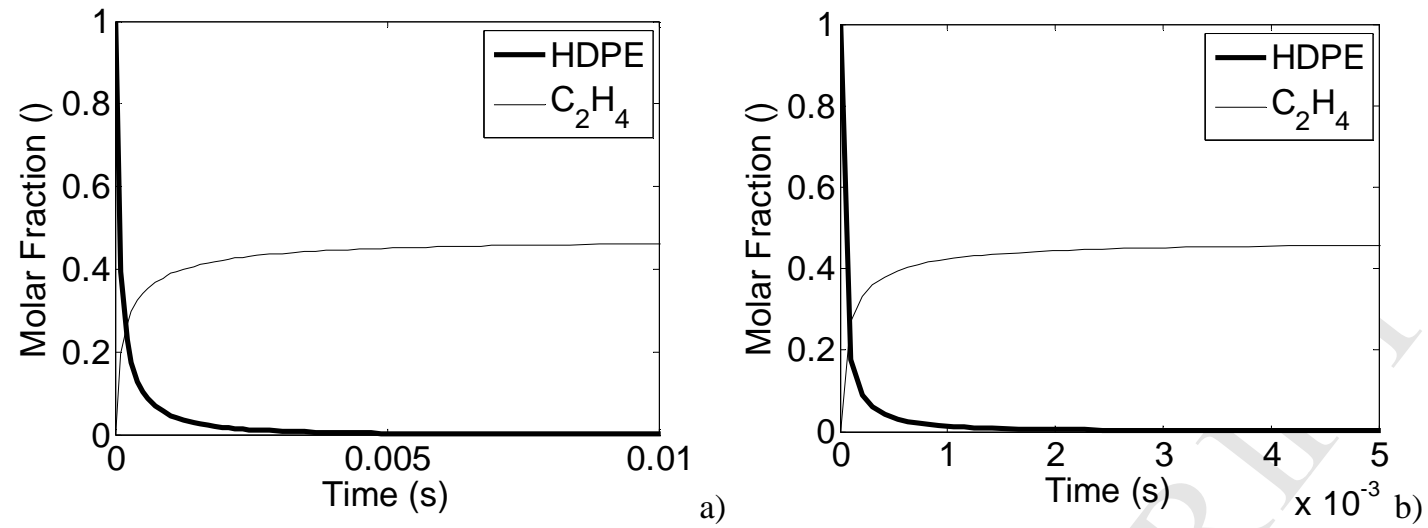

458

459

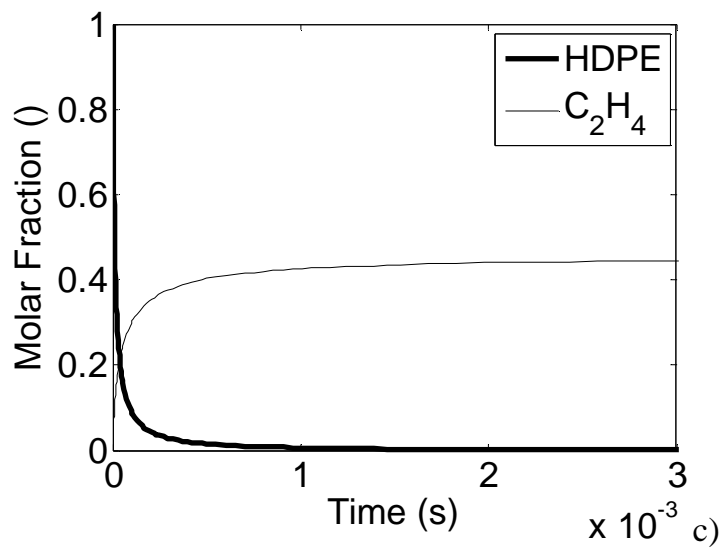

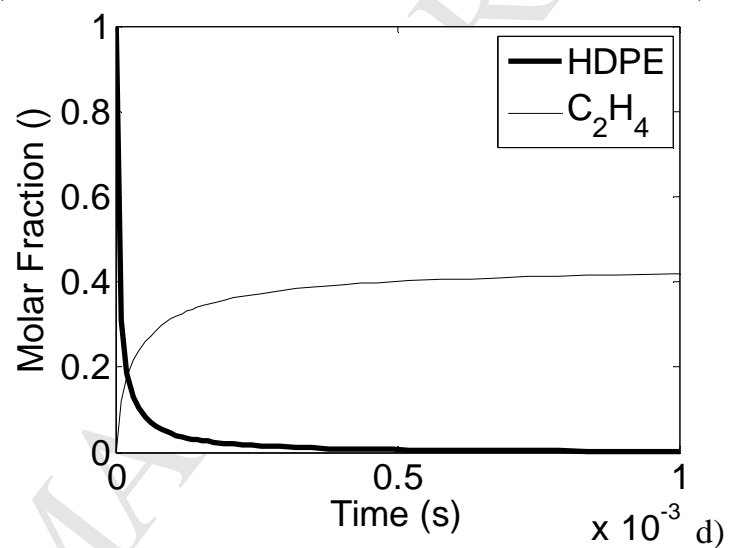

460 Figure 10. HDPE consumption and $\mathrm{C}_{2} \mathrm{H}_{4}$ production at $1200 \mathrm{~K}$ and $1 \mathrm{bar}(\mathrm{a}), 10 \mathrm{bar}(\mathrm{b}), 34 \mathrm{bar}$ (c), $100 \mathrm{bar}(\mathrm{d})$ 

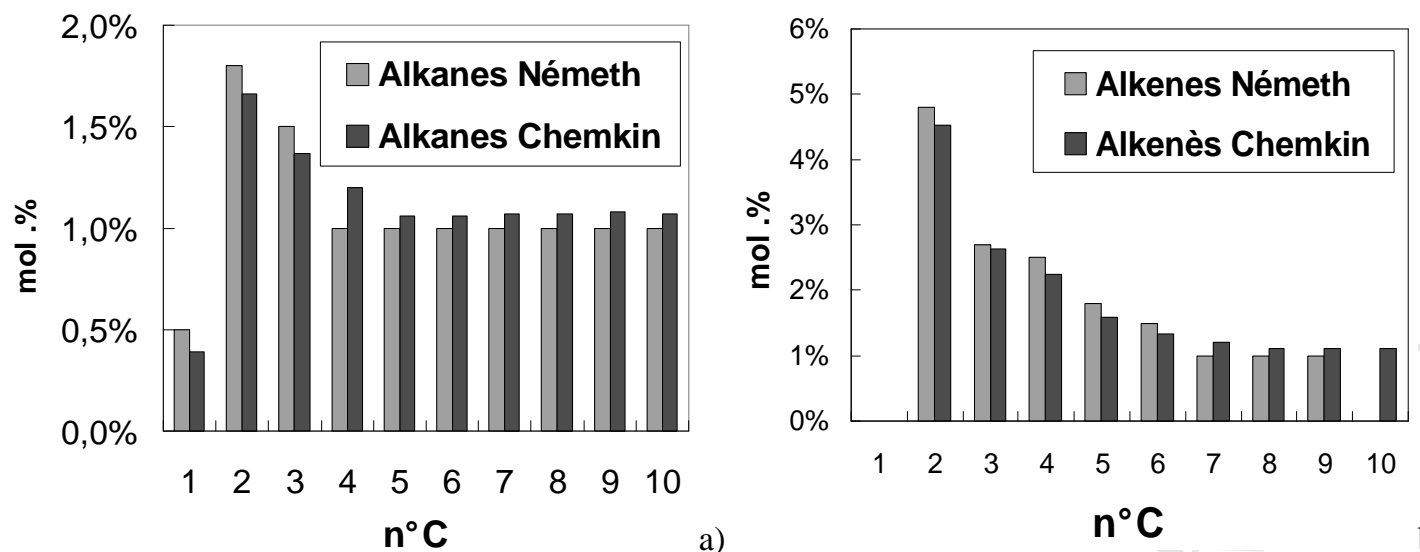

461

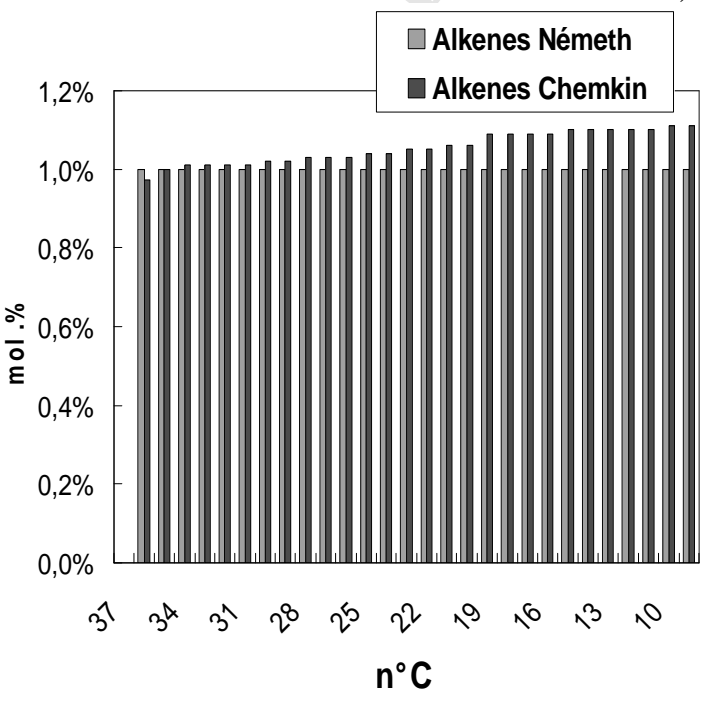

462

463

464

465

466

467

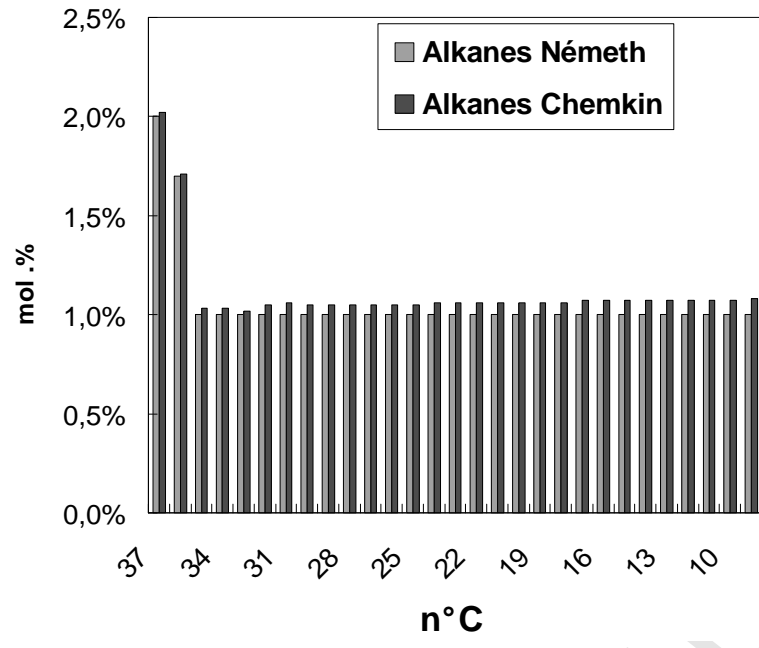

c)

Figure 11 Comparison between Németh et al.' experimental products distribution data (at 1 bar) and numerical results (at 112 bar) at $773 \mathrm{~K}$ and $20 \mathrm{~s}$ of reaction time for gaseous alkanes (a) and alkenes (b) and for non gaseous alkanes (c) and alkenes (d). 